The world's oldest fiscal watchdog: CPB's analyses foster consensus on economic policy

Frits Bos

Coen Teulings 



\title{
The world's oldest fiscal watchdog: CPB's analyses foster consensus on economic policy ${ }^{1}$
}

\author{
Frits Bos $^{2}$ and Coen Teulings ${ }^{3}$
}

\begin{abstract}
The sovereign debt problems in European countries have increased the interest in fiscal watchdogs. This paper discusses the world's oldest fiscal watchdog, CPB Netherlands Bureau for Economic Policy Analysis (CPB). CPB was founded directly after World War II. It has built a reputation of independence and quality, while it has also achieved a solid position in Dutch policy making. CPB provides (i) the macroeconomic forecast underlying the annual budget, (ii) a midterm review of the state of public finance at the start of each election cycle, (iii) cost-benefit analyses of all kind of policy proposals (from education to physical infrastructure), and (iv) an assessment of the economic impact of the platforms of political parties before the election.

Four lessons can be drawn from 65 years of Dutch experience. Firstly, a reputation of quality and independence is crucial for the success of a watchdog. Building such a reputation takes time. Secondly, the scope of activities should not be limited to fiscal policy only. The broad scope of CPB's analyses has contributed to shared public understanding of relevant trade-offs and policy options. Thirdly, the effectiveness of CPB depends crucially on a clear demarcation of the distinctive roles of CPB and political parties. Welfare theory provides little guidance in drawing this demarcation line. Fourthly, being part of the government has the advantage of getting inside information and being effective in the daily policy making process, but the disadvantage that the actual or perceived independence is more difficult to maintain.
\end{abstract}

JEL codes: A11, E62, H6, N4.

Key words: Independent fiscal institutions, National fiscal councils, Fiscal policy, CPB, Tinbergen, History of economic policy in the Netherlands.

\footnotetext{
${ }^{1}$ This paper will be published in G. Kopits (ed.), 2012, Restoring Public Debt Sustainability: the Role of Independent Fiscal Institutions, Oxford University Press. The authors would like to thank George Gelauff, Edwin van der Haar, Albert Jolink and Wim Suyker for comments on an earlier draft.

${ }^{2}$ CPB Netherlands Bureau for Economic Policy Analysis, email: F. Bos@cpb.nl.

${ }^{3}$ CPB Netherlands Bureau for Economic Policy Analysis and University of Amsterdam, email: C.N.Teulings@cpb.nl.
} 


\section{Introduction}

The sovereign debt problems in European countries have increased the interest in fiscal watchdogs. This paper discusses the world's oldest fiscal watchdog, CPB Netherlands Bureau for Economic Policy Analysis (CPB). In 2010, CPB celebrated its 65th anniversary. In the course of its lifetime, CPB has obtained a strong position in Dutch society. It is a widely trusted source of economic analyses on sensitive issues like the short run macro-economic forecast, the mid and long term prospects for public finance, cost-benefit analyses of all kind of policy proposals (running from tax policy to social security and from education to physical infrastructure). CPB's reputation is such that prior to a general election, political parties ask CPB to give an assessment of the economic consequences of their election platforms. Though participation in this assessment is voluntary, all major parties participated. CPB plays therefore a central role in the Dutch debate on economic policy. ${ }^{4}$ The Dutch institutional set up for economic policy with a prominent role for CPB has widely been reviewed as a success, see IMF (2006) and OECD (2010).

How has this success been achieved? This paper investigates the major ingredients of this success. The structure of this paper is as follows. Section 2 describes the history of CPB. Section 3 discusses the institutional framework for budgetary policy in the Netherlands, both for the preparation of the annual budget and for the four-year election cycle. Section 4 discusses the formal arrangements and established practices to ensure CPB's independence, quality and relevance. Section 5 concludes.

\footnotetext{
${ }^{4}$ Debrun et al. (2012) try to measure the impact of CPB on Dutch fiscal policy. Using monthly media information, they show that CPB is successful in drawing attention in the media, in particular in times of budgetary interest, e.g. when the fiscal outturn is significantly worse than the budgetary forecast or when the budget forecast is exceeding the budget ceiling.
} 


\section{History $^{5}$}

CPB started operations in 1945, shortly after World War II. It was formally instituted under the name of 'Centraal Planbureau' (Central Planning Bureau) by the Law of April 21, 1947, containing the preparation of the assessment of a Central Economic Plan. 'Centraal

Planbureau' is somewhat of a misnomer, actually. CPB never did any planning in the sense of issuing administrative guidelines for managing the Dutch economy. ${ }^{6}$ Right from the start the Bureau emphasised macroeconomic assessment and forecasting, and the annual Central Economic Plan has never contained any guidelines. But the name Centraal Planbureau is so engrained in the Netherlands that it would not pay to change it. Internationally, however, CPB presents itself as CPB Netherlands Bureau for Economic Policy Analysis.

CPB benefited from the broad reputation of Jan Tinbergen, who served as its first director. Tinbergen is one of the founding fathers of econometrics for which he received the first Nobel Prize in Economics. The outstanding qualities of Jan Tinbergen both as an economist, as a political advisor, and as a moral authority contributed to the appreciation of CPB work. However, even then it took time for CPB to become embedded in the official decisionmaking process and to build a reputation outside the political arena ${ }^{7}$.

The first major contribution of CPB in Dutch fiscal policy was the government budget of 1946, which was accompanied by estimates on the national economy by $\mathrm{CPB}^{8}$. In this way, the Ministry of Finance's estimates of public revenues and expenditures became linked to the CPB-estimates of the national economy. As a consequence, the Ministry of Finance had no longer a say on the forecast of economic growth, unemployment, inflation and wage rates, limiting the Ministry's ability for political manipulation. It served the Ministry by enhancing the credibility of the forecasts in negotiations with the spending departments. Furthermore, as part of its macro-economic forecasts and analyses, CPB started to provide a regular macroeconomic perspective on public finance; this covered not only the State Budget and its consequences, but also the budget of local government and social security funds.

\footnotetext{
${ }^{5}$ On the history of CPB, see Boogaard (1998), Don and Verbruggen (2006), Passenier (1994) and Van Zanden (2010). On the history of the Dutch fiscal framework, see Bos (2008b).

${ }^{6}$ Unlike the emergency government Schermerhorn-Drees appointed by the Queen, the first elected Dutch government after the Second World War did not want any strong planning and was clear about willing to reduce the role of government.

${ }^{7}$ Passenier (1994), section 3.4.

${ }^{8}$ Bos (2006) and Bos (2008a).
} 
CPB's influence in Dutch political decision-making really took off with the creation of the Socio-Economic Council (SER) in $1950^{9}$. This council consists of representatives from employers' organisations, trade unions and independent experts. The SER's function is to advise the Dutch government on social and economic policy. The director of the CPB is member of the SER and CPB provides technical support for some reports by the SER.

\section{Table 2.1 Major events in the evolution of CPB and Dutch fiscal policy}

\begin{tabular}{|c|c|}
\hline 1945 & $\begin{array}{l}\text { Start of CPB with Tinbergen as its first director. Pre-war ideas of social planning gradually evolve into } \\
\text { forecasts and analysis about objectives and tools. }\end{array}$ \\
\hline 1946 & $\begin{array}{l}\text { Central government budget based on CPB's estimates of the national economy and CPB starts to } \\
\text { provide a regular macro-economic perspective on Dutch public finance }\end{array}$ \\
\hline 1950 & Start of Socio-Economic Council \\
\hline 1953 & First CPB-macro model for analysing and forecasting the Dutch economy \\
\hline 1961 & $\begin{array}{l}\text { In September each year, simultaneously with the Government Budget, a Macro Economic Outlook on } \\
\text { the Dutch economy is published, including estimates of Dutch public finance }\end{array}$ \\
\hline 1971 & First advisory group on fiscal policy; CPB is one of the participants \\
\hline 1975 & $\begin{array}{l}\text { Supply side included in macro-model (clay clay vintage-production function ), which substantially } \\
\text { changed policy recommendations }\end{array}$ \\
\hline 1986 & First analysis of the economic consequences of the election platforms of political parties \\
\hline 1992 & First applied general equilibrium model for the labour market (MIMIC) \\
\hline 1992 & First long term scenario analysis stressing the role of institutions (Scanning the future) \\
\hline 1993 & $\begin{array}{l}\text { Start of first major study on economic institutions: a comparison of economic institutions in Germany } \\
\text { and the Netherlands }\end{array}$ \\
\hline 1994 & Cost-benefit analysis of railway freight track to Germany (Betuwelijn) \\
\hline 1998 & First analysis of sustainable public finance (generational accounts) \\
\hline 2000 & National guidelines by CPB on cost-benefit analysis \\
\hline
\end{tabular}

CPB's first macro model became operational in 1953. It served as a basis for forecasting and policy advice for most of the 1950s. This was path-breaking, as modelling was viewed as a merely academic exercise at the time. The model was used to draft a table with the expected consequences of particular policies. The table enabled decision-makers to choose their favourite policy menu. This table reflected Tinbergen's view on planning: policy makers should define the targets of government policy while the optimal mix of instruments for achieving these targets should be picked on the basis of an economic model. ${ }^{10}$

\footnotetext{
${ }^{9}$ See Passenier (1994).

${ }^{10}$ See Tinbergen (1956) for an elaboration of these ideas.
} 
The trend based government deficit norm was introduced in $1961 .{ }^{11}$ A major purpose was to provide a multi-annual benchmark for the budget deficit, thereby providing a defence against the claims from politicians and lobby-groups on the budget. This worked reasonably well, till the early 1970s, when both the economy and public finances started to deteriorate. The pressure to circumvent budgetary rules increased drastically. In 1971, the first advisory group on fiscal policy ('Studiegroep Begrotingsruimte') was therefore asked to provide stricter rules. Since then, this committee has reconvened before every general election to provide such an advice for the next government, as will discussed in Section 3.

After the first oil crisis in 1974, the Dutch economy entered a stage of stagflation with simultaneously high inflation and high unemployment. The average annual growth rate of GDP declined from $5 \%$ to $2 \%$. As a consequence, the small government budget surplus was succeeded by a deficit of $3 \%$ in 1975 . The economy suffered from the "Dutch disease": the availability of large natural gas resources raised disposable income and drew labour supply towards the domestic sector for the provision of non-tradables. The export sector lost competitiveness. Moreover, the natural gas resources were spent to finance among others a large disability insurance scheme, which drew away almost a million workers from labour supply. CPB provided an analysis of the stagnation of the Dutch economy, by pointing to excessive increase in labour cost, which eroded the competitiveness of the Dutch economy. The policy recommendation to reduce wage growth was illustrated by a new macro model, the VINTAF model (Hartog and Tjan, 1976). Previous CPB models were Keynesian models which stressed the importance of the demand side of the economy. In the VINTAF model, the negative effects of high wage rates on production capacity were made explicit. The VINTAF model and its policy recommendations were subject to heated debates among Dutch economists and politicians. Gradually, CPB's ideas became broadly accepted. The pleas by CPB for lower wage growth became effective in the early 1980s.

In 1986, CPB started the evaluation of election platforms. Following a request from the three major political parties, $\mathrm{CPB}$ analyzed the economic consequences of their election platforms. To what extent would these proposals help to increase economic growth and improve public finance? And what would be the consequences for unemployment and the disposable income of various groups of households? CPB prepared for each party a separate paper. These three papers were published jointly after the election. Since then, both the scope of the analysis and

\footnotetext{
${ }^{11}$ See Bos (2008a).
} 
its impact on the popular debate has been increased. Section 3 provides a detailed description of the current state of the evaluation of election platforms.

In the second half of the 1980s, the supply-side effects of the high (marginal) tax rates and social security contribution and of the generous unemployment benefits drew more attention in the policy debate, following previous analyses supply side economists, mainly from the US. The adversary effects of high tax wedges were also a main issue in the policy advices of the OECD during this period. However, CPB's macro-model largely neglected these supplyside effects. CPB invested heavily in closing the gap. It took five years to build an applied general equilibrium model for the labour market (MIMIC) ${ }^{12}$. Again, CPB's new ideas on the importance of financial incentives for labour supply lead initially to an extensive discussion among economists and politicians. Gradually, these ideas became broadly accepted. Also parties on the left, for which the disincentive effects of taxes and unemployment benefits on labour supply are traditionally hard to accepted, got convinced by the mechanisms embedded in MIMIC. From 1992 onwards, MIMIC has been used frequently for policy analysis. The model also played an important role in the evaluation of election platforms. Donders and Graafland (2000) claim that the success of MIMIC in the Dutch policy debate is due to its ability to reproduce many intuitions of policy makers about the impact of taxes and social security on the economy in a systematic and scientific way.

The CPB started developing long-term scenarios already in 1950. The first scenarios stressed the uncertainties involved in macro-economic forecasting and the need for policy and the economy to be flexible in view of such uncertainties. The importance of institutions and different views on the economy and the role of government were explicitly acknowledged for the first time in the long-term scenarios of 1992. The study 'Scanning the Future' (CPB, 1992a) presented four long-term scenarios for the world economy, based on a SWOTanalysis. Three competing perspectives on long term economic growth were distinguished: an equilibrium perspective based on neo-classical growth theory, a Keynesian coordination perspective with an important role for the government and a free market perspective with uncertainty and imperfect information and a major role for entrepreneurship. The study 'The Netherlands in triple' (CPB, 1992b) elaborated these scenarios for the Dutch economy. This analysis was a synthesis of CPB's traditional quantitative modelling approach and qualitative analysis. It provided a framework for strategic policy decision-making by identifying crucial

\footnotetext{
${ }^{12}$ See Gelauff and Graafland (1994) and Graafland et al. (2001).
} 
trade-offs and bottlenecks. Again, the scenarios were widely debated. They turned out to be useful for focussing policy makers on a program to improve the market institutions.

The long term scenario studies stressed the importance of institutions. They were the first step towards more detailed institutional analyses of CPB. In 1993, CPB started a comprehensive comparison of German and Dutch institutions (CPB, 1997). This study helped to draw the attention of policy makers and politicians to the failures of government ánd markets. It clarified to a broad Dutch audience why both the German and the US institutions could be successful in generating economic growth and welfare. Since then, CPB has published regularly institutional analysis of specific sectors, e.g. social security, health care, and education.

In the mid-1990s, government planned a freight railway-track from the Rotterdam harbour to Germany. This plan reintroduced cost-benefit analysis (CBA) at CPB ${ }^{13} \mathrm{CPB}$ took the initiative to make a CBA of the project. The costs of the project were shown to greatly exceed the benefits. CPB's conclusions invoked an outcry of critique, both from stakeholders and from the government. The CBA was disregarded and the project was executed as planned. With the benefit of the hindsight, CPB's conclusions were largely correct. Despite the failure to affect decision-making in this particular case, CPB's initiative led to a reappraisal of the value of CBA's. Since 2000, there are national guidelines on CBA's. These guidelines guarantee that all CBA's are based on the same assumptions and methodology. All major infrastructure projects financed by the Dutch central government are now subject to CBA's based on these guidelines. Actually, many CBA's are not done by CPB itself, but CPB provides a second opinion on their quality and the compliance to national guidelines. In 1997, CPB started the calculation of generational accounts for the Netherlands, following the seminal work by Auerbach, Gokhale and Kotlikoff (1991). For an economy in a steady state, the current budget deficit is a sufficient statistic for the evaluation of the viability of a country's public finances. However, due to the rapid ageing of the population in most European countries, their economies were not at all in steady state. Future deficits are expected to be much higher, due to public health care and pension liabilities. Generational accounting is an indispensable tool to show the magnitude of these liabilities and hence the sustainability of current institutions. Again, the first publication led to an extensive policy

\footnotetext{
${ }^{13}$ Under the supervision of Tinbergen, CPB made a cost-benefit analysis of the Deltaworks (a plan to raise dykes after massive flooding of some parts of the Netherlands in 1953) in 1954. After budget cuts in the early eighties, such project appraisals were scrapped at CPB.
} 
debate among economists and policy makers. In response to these debates, the analysis has been gradually improved. By now, this forward looking approach of generational accounting is accepted as the new paradigm for Dutch public finance. As we will see in Section 3, generational accounting plays therefore a major role in the evaluation of election platforms.

What lessons can be learned from this history? The first lesson is that coming engrained in the official decision-making process and earning a reputation of quality and independence takes time. At the start in 1945, staff and government had only a very vague idea about the tasks and mission of CPB. Step by step and case by case, CPB managed to affect the policy debate by demonstrating main trade-offs to policy makers and to the wider public. The shared understanding of these trade-offs helped to achieve political support for policy reforms. Since these reforms affect the interest of large pressure groups, it is not at all surprising that such a reputation and impact cannot be achieved overnight.

The second lesson is that a fiscal watchdog should define its scope broadly. The CPB has always done work in a broad spectrum of societal issues. In this way, the bureau has provided insights in major political issues in the Dutch society. The history of CPB shows some clear successes in influencing public debate and ultimately government policy, e.g. the reduction of wage growth in the 1970s, the importance of incentives for labour supply in the 1990s, and the introduction of generational accounting at the end of the 1990s. However, CPB was not always successful in guiding the public debate with up-to-date economic insights. For example, when the budget deficit and the government debt got out of hand in the early 1980s and the new government set out for a policy based on supply-side economics, it took CPB some years to realize the importance of these new views. Hence, CPB played little role in the large policy shifts in the early 1980s. Only, in the 1990s, CPB regained its position after the construction of its micro-simulation model MIMIC. Similarly, the recent financial crisis revealed that $\mathrm{CPB}$ has not properly appreciated the importance of the financial markets. This history shows the importance for a fiscal watchdog of defining its scope broadly. A fiscal watchdog functions most effectively when it seeks a broader scope in the public debate than just the budget deficit. The credibility of a fiscal watchdog benefits from its ability to identify major policy trade-offs early on. This history also shows that acquiring the knowledge and skills for providing a balanced set of good quality analyses that takes well account of the specific features of a national economy takes substantial time. 


\section{3. $\mathrm{CPB}$ in the election cycle and the annual budgetary process}

This section deals with the role of CPB in the core of the budgetary process. ${ }^{14}$ This role has two parts: the 4 yearly-election cycle and the annual budgetary process.

Elections for a new parliament are held once every four years or earlier on, whenever the government loses confidence in parliament. The Netherlands has a multi-party system where no single party ever had a majority in the parliament. As a consequence, immediately after the election, a number of parties controlling a majority in parliament agree on a program for the next government. This program stipulates the plans for the next four years. There is a tendency for this agreement to become increasingly detailed, since parties find it difficult to compromise on issues halfway the election cycle, therefore they prefer to settle at the start of the period. CPB plays an important role in this process. It sets the economic framework for the next election period in its mid term outlook. Most remarkably, CPB evaluates the election platforms of political parties before the election. The publication of this evaluation is a major media event during the election campaign. After the election the parties that intend to form a coalition negotiate on the program for the new government on the basis of the evaluation of the election platforms of CPB. When the negotiations are finished, CPB evaluates this program on the same basis as the election platforms. In this way, both evaluations are comparable. In these roles, CPB operates close to the demarcation line between expert judgment and politics. This requires clear rules of conduct that have to be based on a common understanding by both CPB and the political parties. As we will argue, welfare economics provides only partial guidelines for how exactly to draw these demarcation lines. In the years during and between two elections, CPB is heavily involved in the process for the preparation of the annual budget. CPB provides the official forecasts for GDP, unemployment and inflation and analyses their impact on the public expenditure, on tax revenues, and on the implied budget deficit. The coalition agreement provides yardsticks for these three statistics that may depend on the state of the economy. The role of CPB is to monitor to what extent the government lives up to these yardsticks. Again, CPB's role is on the demarcation line between expert judgment and politics. Section 3.1 discusses the role of $\mathrm{CPB}$ in the election cycle; section 3.2 discusses its role in the annual budgetary process.

\footnotetext{
${ }^{14}$ For a general overview of CPB in Dutch policy making, see also Bos and Teulings (2010) and Butter (2009).
} 


\subsection{The election cycle and the evaluation of election platforms}

Table 3.1 The road to a new medium-term fiscal framework in five steps

\begin{tabular}{ll}
\hline One year before the elections & Step 1. Medium and long term forecast for the economy by CPB \\
One year before the elections & Step 2. Report by the Advisory Group on Fiscal Policy \\
2 months before the elections & Step 3. Evaluation of election platforms by CPB \\
After the elections & Step 4. CPB-analysis of the coalition agreement \\
Some months after the elections & Step 5. The new medium-term fiscal framework
\end{tabular}

The election cycle involves a number of steps that are listed in Table 3.1

\section{Step 1 Medium and long term forecast by CPB}

One year before the elections, the road to a new coalition agreement starts. CPB makes a forecast for the Dutch economy and public finance for the next period of government assuming that there is no change in current policies. Furthermore, CPB provides an analysis of the long run sustainability of Dutch public finance taking the current tax system and the organisation of public services as health care, education, and public pensions as given (see e.g. Horst et al. 2010). This forward looking approach of generational accounting is the new paradigm of Dutch public finance. ${ }^{15}$

Public finance is said to be sustainable if current public arrangements can be maintained "for ever" without public debt exploding. CPB provides an estimate of the percentage of GDP that either government expenditure has to be reduced or tax revenues have to be increase for the public finance to become sustainable. This is the so-called sustainability gap. According to CPB calculations, the coalition agreement of the government under Prime Minister Rutte that started in 2010 implies that the sustainability gap will be reduced by $3 \%$ GDP, leaving a sustainability gap to be solved by future generations of about $1 \%$ GDP.

Sustainability of public finance could be regarded as a problem on the distribution of income over generations. Without timely adjustments future generations should have to accept a drastic deterioration of public arrangements. By timely adjustments the net benefit from public arrangements will be spread more evenly over the different generations. CPB analyses on the sustainability of Dutch public finance therefore also show the impact of specific policy measures on the distribution over different generations.

\footnotetext{
${ }^{15}$ See also section 2 and Bos and Teulings (2011), in particular sections 2.4 and 3.5.
} 
The analysis of sustainability is a financial check on government policy. However, it does not provide a criterion which policy measures are preferable from a welfare point of view. Innovations in medical technology can raise life expectancy and have therefore a high social rate of return. But in terms of sustainability, public investments in medical research score badly, as they do not only increase public expenditure, but they also increase life expectancy and therefore old age public pensions. All public expenditure should be financed. This applies also to expenditure on infrastructure, education or future environmental quality.

\section{Step 2 Report by the Advisory Group on Fiscal Policy}

The next step is the report of the Advisory Group on Fiscal Policy. This Advisory Group is commissioned by the cabinet. The cabinet makes explicit which topics should be addressed in its report. The Advisory Group evaluates past budgetary procedures and makes recommendations for the fiscal targets and rules for the next election cycle. The Ministry of Finance provides the secretariat of the advisory group. CPB's medium and long term forecast are an important input. CPB is often asked for analyses on specific issues. The report provides an advice on the budgetary policy that is required for long term sustainability. Furthermore, the report provides detailed rules of conduct in case either revenues, or expenditures, or the general economy will deviate from the forecasted time path half way the election period. These rules are crucial, since it turns out to be very difficult to come to reach agreement on budget cuts half way the election period.

In general, expenditure is fixed at the start of the government for the whole election cycle. There are expenditure ceilings for three broad categories (social security and labour market, health care and other expenditure by central government), which are then broken down by spending ministry. Each ministry is responsible for keeping expenditure below its preset ceiling. Hence, excess spending on one item should be compensated by lower spending on other items within the budget of the own ministry. This avoids disputes between individual ministers in case of excess of spending.

The rules for revenues are different. Tax rates and other tariffs are fixed at the start of the period. Any subsequent changes in revenues due to changes in rates should be compensated by offsetting rate changes elsewhere. On the contrary, variations in revenues due to the business cycle do not require offsetting policy changes. Hence, revenues act as an automatic stabilizer. By making different rules for expenditure and revenues and by requiring 
compensation within the budget of the own ministry, the rules eliminate the option to resolve excess spending problems half way the election period by raising taxes. This helps in keeping marginal tax rates under control. History has shown that without this type of rules a coalition government tends to counter excess spending by higher taxes.

This is the general framework as it emerged during the past 20 years. ${ }^{16}$ Needless to say, there have been many attempts to circumvent the rules by clever reinterpretation during the period the government stays into office. For example, the distinction between lower revenues and higher expenditure is not always that sharp. A subsidy can either be administered as spending or as a tax deduction. Details of the rules are therefore changed every period to close loopholes. The Advisory Group makes a proposal for these changes. This proposal for new rules is usually largely accepted by the political parties forming the new government. By and large, the system works well.

The main weakness is that all adjustment to structural economic shocks is relegated to the negotiations on a new coalition, usually once every four years. When GDP and hence tax revenue is structurally lower than expected by CPB at the moment that these negotiations took place, the rules do not require the government in power to adjust its fiscal policy to accommodate this negative shock. Only after the next election, during the negotiations on the subsequent coalition program, the adjustment takes place. Hence, it would be desirable to have a framework for analysing to what extent shocks are structural and what would be the optimal response for fiscal policy. This topic is currently addressed by CPB in its ongoing research program.

\section{Step 3 Evaluation of election platforms by $\mathbf{C P B}^{17}$}

A unique feature of the Netherlands is that CPB publishes an analysis of the economic effects of election platforms of political parties. This evaluation serves a number of goals, some of them intended when the first evaluation was conducted in 1986, some of them evolved over time.

\footnotetext{
${ }^{16}$ For more details, see Bos (2008a).

${ }^{17}$ A more detailed discussion can be found in Bos and Teulings (2011).
} 
Firstly, discussions with CPB help political parties to improve their program. Many policies initially proposed by parties have unintended consequences. This applies in particular to all kind of tax proposals. CPB systematically investigates proposals and helps improving them on the technical side. In practice, many proposals are adjusted during the process, following CPB's advice. CPB also conducts a test on technical and legal feasibility. Policies that fail on this test are excluded from the evaluation. In order to be evaluated properly, policy proposals often also have to be clarified and made more concrete.

Secondly, an effect not foreseen in the first evaluation in 1986 was that the evaluation turned out to be a great help to facilitate negotiations between political parties on the program for a new government. By having a common denominator for the calculation of cost and revenues of all proposals, disputes about facts are avoided during the negotiations. The same underlying economic scenario is used to evaluate each election platform, so that differences in outcomes cannot be due to diverging assumptions about the economy. Since CPB evaluates the proposals of all parties in uniform way, the parties cannot exaggerate the benefits and/or understate the costs of their proposals, apply accounting tricks, or enjoy free lunches. ${ }^{18}$ Moreover, the proposals are presented in the same way, so that parties' commitments can be compared to each other.

Finally, the evaluation plays a major role during the election campaign. The evaluation is published several weeks before the election. CPB tries to publish at least 12 weeks before, but this is not always feasible in practice, in particular when the elections are held unexpectedly due to the fall of government. By publishing well ahead of the election CPB tries to limit its direct impact on the election outcome. CPB conducts this evaluation at the request of each political party and a party that does not want its platform to be included in the evaluation is left out. In practice, all major political parties participate in the analysis. The revelation principle is at work here, because by not participating in the evaluation, a party signals to voters that its program is economically and financially unsound.

CPB stresses time and again that the evaluation of platforms is not an exam. The evaluation only provides insight in the consequences of its implementing. Any platform is acceptable; they just reflect different sets of political preferences. It is up to the voters to decide what

\footnotetext{
${ }^{18}$ Examples are using central government's natural gas reserves or the financial assets of social security funds or private housing corporations to 'finance' extra government expenditure or to reduce taxes.
} 
platform they prefer. Nevertheless, the evaluation is depicted as an exam for the parties in the press. Political parties spend a lot of effort in the process and are quite nervous about the result. Journalists use the evaluation in the final weeks before the elections as a data-base for critical articles and interviews.

Key indicators of the evaluation are the implications of the proposals for budget deficit, purchasing power, and the economy in general. ${ }^{19}$ Expenditures are reported by sector of ministry as to document the differences between the platforms. CPB provides an in depth analysis of the implications of the platforms for specific sectors, like education (as it is an important factor explaining future growth), the housing market (as it is heavily distorted), infrastructure, climate change, and health care. Finally, the CPB provides insight in the long run sustainability of public finance, using its generational accounts. Providing these long run estimates requires $\mathrm{CPB}$ to make an assessment of the long run impact of proposed policies. For example, a gradual increase in the retirement age contributes to the long run sustainability of public finance. However, the implementation of this type of policies will last far beyond the current election cycle. In order to avoid that political parties come up with proposals which become effective only far beyond the next election date, CPB only includes policies that have at least some impact on actual disposable income of households or business during the next election cycle. Even then, political parties are quite creative in designing proposals that improve the sustainability of public finance in the long run but do not affect any interest group during the next government period. Table 3.2 provides an overview of the main indicators for specific topics for each party used in the last evaluation.

\footnotetext{
${ }^{19}$ The reported economic indicators are the long run effect on GDP, employment and unemployment, wages, and inflation. The effect on purchasing power may differ widely between types of households. These effects are therefore expressed in a scatter diagrams for various groups of households and levels of initial income.
} 


\begin{tabular}{|c|c|c|c|c|c|c|c|c|c|}
\hline & CDA & PvdA & SP & VVD & PVV & GL & ChrU & D66 & SGP \\
\hline Improvement EMU-balance in 2015 (euro bln) & 18 & 11 & 10 & 20 & $15^{3 / 4}$ & $10^{1 / 4}$ & 16 & $143 / 4$ & 18 \\
\hline Sustainability of public finances (euro bln) & 33 & 31 & 16 & 39 & 17 & 35 & 35 & 37 & 32 \\
\hline Purchasing power of households in 2015 (euro & & & & & & & & & \\
\hline $\begin{array}{l}\text { bn) } \\
\text { Profits of companies (including housing }\end{array}$ & $-3 \frac{1}{2}$ & $+1 / 4$ & $+1 \frac{114}{4}$ & $-1 \frac{1 / 2}{2}$ & -2 & 0 & $-23 / 4$ & -3 & -8 \\
\hline corporations) (euro bln) & +1 & -1 & $-41 / 4$ & $-1 \frac{1}{4}$ & $-23 / 4$ & $-41 / 4$ & $-43 / 4$ & $-13 / 4$ & $-1 \frac{1 / 4}{2}$ \\
\hline Structural employment (\% point) & 4 & $2^{1 / 2}$ & -1 & $53 / 4$ & $1 / 4$ & $4 \frac{1}{2}$ & $1 \frac{1}{4}$ & $33 / 4$ & $2 \frac{1}{2}$ \\
\hline $\begin{array}{l}\text { Accessibility by public or private transport } \\
\text { (welfare gain, bln euro) }\end{array}$ & $3 / 4$ & $3 / 4$ & $-1 / 4$ & $1 / 4$ & $1 / 4$ & $-1 / 2$ & $1 / 2$ & $3 / 4$ & $1 / 2$ \\
\hline Car usage $(2020$, in \%) & $10-15$ & $10-15$ & 0 & 0 & 0 & -20 & $-10-15$ & $-10-15$ & -15 \\
\hline Public transport usage $(2020$, in \%) & $5-10$ & $5-10$ & +5 & 0 & 0 & +15 & $5-10$ & +10 & $+5-10$ \\
\hline Reduction of greenhouse gases (Mton Co2) & 36 & 44 & 21 & 2 & 2 & 63 & 38 & 31 & 28 \\
\hline Quality of nature (2020) & 0 & + & + & -- & - & ++ & $0 /+$ & $0 /+$ & 0 \\
\hline Quantity of nature (2020) & 0 & + & $0 /-$ & -- & - & + & 0 & $0 /+$ & - \\
\hline GDP effect education (structural, \%) & $2 \frac{1}{4}$ & $43 / 4$ & $1 / 4$ & 4 & $1 / 4$ & $41 / 4$ & $13 / 4$ & $31 / 4$ & $31 / 4$ \\
\hline Science/innovation (budget, bln euro) & -0.07 & -0.2 & -0.06 & -0.1 & -1.2 & +0.4 & -0.33 & +0.2 & +0.22 \\
\hline Housing market (welfare gains $\%$ gdp) & 0.1 & 0.5 & 0.4 & 0.3 & -0.1 & 0.8 & 0.5 & 0.9 & 0.7 \\
\hline Change in housing prices $(2015, \%)$ & -1 & -7 & -6 & -2 & 0 & -6 & -5 & -10 & -6 \\
\hline Change in net rent $(2015, \%)$ & 5 & 1 & -3 & 10 & 0 & 6 & 6 & 10 & 8 \\
\hline Health care, employment, 2015, thousand ) & -10 & -15 & +15 & -50 & +10 & +15 & -30 & -40 & -35 \\
\hline \multirow[t]{2}{*}{ Own risk health insurance (2015, level, euro) } & 230 & $200-$ & 0 & 300 & 210 & $150-$ & $200-$ & $210-$ & $150-$ \\
\hline & & 600 & & & & 300 & 600 & 400 & 500 \\
\hline $\begin{array}{l}\text { More (+) or less (- ) market forces in health } \\
\text { care (cure-part) }\end{array}$ & + & $0 /+$ & -- & ++ & 0 & $0 /+$ & + & ++ & + \\
\hline
\end{tabular}

There is an extensive public debate on the merits of this exercise. ${ }^{20}$ The main objections seem to be threefold.

First, the exercise might constrain the political debate too much, by CPB disapproving proposals on what are presumably technical arguments. For some topics, this might be asking too much of what economic science is able to provide. CPB therefore deliberately restrains its judgement to avoid excessive interference in topics which economists might interpret as merely positive issues that can be settled by purely positive economic arguments, but which political parties -and society in general- consider to be political issues. Taken to the extreme, economists would view only the income distribution within and between generations as a topic that requires a normative and hence political judgement. All other issues could be

\footnotetext{
${ }^{20}$ On the merits and limitations of this analysis, see also the papers in Graafland and Ros (2003).
} 
decided upon on the grounds of Pareto efficiency, using market prices or other indicators of revealed preferences of citizens for particular outcomes as a way to aggregate. However, CPB is reluctant to use concepts like Pareto efficiency or a Hicks-Kaldor welfare criterion in the evaluation of election platforms. ${ }^{21}$ These concepts try to settle debates on technical grounds which are in fact highly political. For example, political parties have strong views on the trade off between leisure and market activity, where economists might just use the wages as the price of leisure and leave it to the individual to decide how much (s)he wants to work. An increase in GDP at the expense of lower leisure might therefore have a zero impact on efficiency / Hicks-Kaldor welfare. However, CPB reports the effect on GDP and not on welfare. It leaves the choice between output and leisure to political parties. Similarly, whether or not to introduce markets in health care is an issue that in theory can be settled purely on efficiency grounds. However, political parties have a priori views on this issue which cannot be reduced to efficiency alone. ${ }^{22}$ By focussing on efficiency, the evaluation of election platforms would interfere in this debate by discrediting the views of particular political parties on the basis of their (perceived) inefficiency. Only for the housing market and cost benefit analyses on infrastructure, CPB applies the Hicks-Kaldor criterion since in these cases there is no alternative indicator to document the cost of the distortion of the housing market or the gain in travelling time. The demarcation line between technical/positive and political/normative issues is therefore set in the course of the public debate rather than by the theoretical insights of welfare economics. CPB contributes to in that debate in between elections, see for example the role of CPB's MIMIC model in making transparent the tradeoff between equity and efficiency, see Section 2. Nowadays this model plays a major role in the evaluation of election platforms. However, changing the public debate takes time and involves many more players than just CPB. During election time CPB refrains from this type of interventions in the policy debate, let alone in the evaluation of the election platforms itself. $^{23}$

\footnotetext{
${ }^{21} \mathrm{CPB}$ uses the Hicks-Kaldor welfare criterion in cost-benefit analysis of infrastructural projects. Whenever possible, effects are quantified and translated into monetary terms, e.g. by using market prices.

${ }^{22}$ This argument cannot be reduced to the standard argument that most policies affect both efficiency and the welfare distribution, and that there are usually no instruments to redress the effect on the welfare distribution.

${ }^{23}$ This relates to the claim by the Commission on the Measurement of Economic Performance and Social Progress (see Stiglitz, Sen and Fitoussi, 2009) that GDP does capture all relevant aspects. However, the Hicks-Kaldor criterion and other welfare concept used in welfare economics are much broader than GDP. Welfare includes any aspect that citizens consider to be relevant, while GDP includes only marketable activities. Many of the objections being raised against using GDP do therefore not apply to the welfare concept. The key difference between welfare and the position taken by Stiglitz, Sen and
} 
Similarly, CPB is careful to include a set of topics in its evaluation that cover the preferences of all political parties to some extent. For example, excess attention for climate change would favour green parties, while ignoring environmental issues would favour parties that do not want to pay too much attention to these issues. ${ }^{24}$ In practice, CPB decides on what topics to cover on the basis of the course of the public debate and on the availability of specific expertise within CPB or economic science in general. Including a new topic requires a long preparation. $\mathrm{CPB}$ has to build up expertise, often in cooperation with specialised researchers from academia. Furthermore, there is extensive discussion with ministries and political parties before $\mathrm{CPB}$ includes a topic, since $\mathrm{CPB}$ wants political parties to have a proper understanding of the way in which the topic will be handled in the evaluation.

A second objection against the evaluation is that the exercise biases the debate in the direction of proposals of which CPB is able to evaluate the effects quantitatively. ${ }^{25}$ For example, the effects of major reform of the institutions in health care -allowing free entry of private hospitals and allowing hospitals to go bankrupt- are hard to assess. Nevertheless, this might to be a sensible idea. How to deal with this type of ideas in the context of an evaluation of the election platforms? This yields a pressure from political parties to include more and more topics in the evaluation and to offer an ever more detailed numerical evaluation. So, while political parties sometimes claim that the evaluation is too inclusive, covering too many topics, there is also pressure from parties to extend the scope of the analysis. Similarly, CPB's scepticism regarding the availability of free lunches might in fact favour small groups of insiders who collect large rents that could potentially be extracted to the benefit of the wider public. The scepticism regarding the feasibility or uncertainty of success of such reforms can acts as a conservative force.

Third, the exercise might bias the debate in favour of the short run implications, since the longer run implications are much more uncertain and materialize beyond the next government period. This is particularly relevant where the short run implications are mainly of Keynesian

\footnotetext{
Fitoussi is that latter refrain from aggregating various aspects into a single statistic, while welfare economics does. By showing the effects of election platforms on a dashboard of indicators without aggregating them (see e.g. table 3.2), the evaluation of election platforms follows Stiglitz, Sen and Fitoussi.

${ }^{24}$ CPB cooperates with another public organization, PBL (Netherlands Environmental Assessment Agency) for the analysis of the effect on climate change and the environment.

${ }^{25}$ As in between category CPB gives only a qualitative evaluation for some policy proposals.
} 
nature and where the long run implications refer to the improvement of economic structure, better incentives and the like. In response to the latter objection, CPB has shifted the attention away from the short run Keynesian effects towards the sustainability of public finance and towards the structural effects on long term GDP, for example due to the reduction of replacement rates. For example, the MIMIC model has been constructed to assess the structural effects of changes in replacement rates and marginal tax rates on labour supply.

The high media coverage and the large role of the evaluation in the election campaign requires $\mathrm{CPB}$ to provide a clear set of rules for how the evaluation is conducted, to take maximum precautionary measures to avoid unfair competition between political parties and leakage of information from one party to another ${ }^{26}$, and how to communicate the conclusion of the evaluation. CPB's evaluation of a party's platform is based on the input submitted by the party. CPB does not check the consistency of this input with other statements of that party, for example the published election platform. Instead, CPB provides an overview of each party's input submitted to CPB in its evaluation. This overview enables other parties and journalists to check for inconsistencies. CPB refrains from a judgment on these issues as to avoid having to take side in a public debate. More generally, CPB refrains from any comment on arguments put forward by political parties during the election campaign, unless the wording of CPB's report causes confusion in the debate.

\footnotetext{
${ }^{26}$ These and various other rules for the evaluation of election platforms are discussed in Bos and Teulings (2011), section 4.
} 
1. Political parties cannot opt out for one or more topics of the evaluation.

2. The baseline projection is a neutral extrapolation based on the assumption of unchanged policy.

3. Only new policy proposals are included; this excludes policy in the baseline projection.

4. The same methodology is used for evaluating the election platforms of all parties.

5. Only policy proposals are included that are sufficiently clear and well-specified.

6. Only policy proposals that can be made (unilaterally) by central government are included.

7. Policy proposals should be legally and practically feasible during the next period of government.

8. Policy measures of which the effects cannot be assessed sufficiently reliably are not included.

9. Policy proposals should have real effects during the next period of government.

\section{Step 4 CPB analysis of the coalition agreement}

Immediately after the election, negotiations start for a new coalition. The report of the advisory Group on Fiscal Policy and CPB's evaluation of the election platforms are a major aid for these negotiations. As soon as a group of parties have agreed to start negotiations, a list of joint proposals of these parties in CPB's evaluation of their election platforms is used as a starting point for the negotiations. CPB's overview serves as a data base on all kinds of policy measures that could be considered during the negotiations; in particular the budget cuts and extra revenue generating measures by other parties are a popular source of inspiration. As part of the bargaining process, when the bargaining is nearly finished, CPB is generally asked to provide an evaluation of the draft coalition agreement based on the same basic methodology as the evaluation of the election platforms. When the bargaining process is completed, CPB also conducts an evaluation of the new coalition agreement.

\section{Step 5 The new medium term fiscal framework}

Finally, the Ministry of Finance sets the fiscal rules and calculates the medium-term fiscal framework, starting from the coalition agreement and the most recent macro-economic forecasts by CPB. For example, the level of the real expenditure ceilings is fixed considering the coalition agreement and the most recent information about expenditure and revenue. Estimates by CPB serve as a critical benchmark for fixing the medium-term fiscal framework; this applies in particular to those on social security, taxes and health care.

This process for deciding on a new coalition-agreement implies that policy measures are checked in an early stage on their feasibility and consequences on the national economy and public finance in the medium term and long run. Before the elections, the policy measures 
proposed by all major political parties are analysed by CPB. In the subsequent steps towards a new coalition agreement, this analysis provides a benchmark for evaluating their effect on the government budget.

\subsection{The annual budgetary process}

The annual budgetary process is summarized in table 3.4. CPB plays a crucial role in this process. CPB publishes quarterly forecasts for the economy. Two of these forecasts are published as special publications with an official status, CEP (Centraal Economisch Plan) in March and MEV (Macro Economische Verkenning) in September. These forecasts are supplemented with an in depth analysis of the state of the Dutch economy, with special attention for topics that are particularly relevant at the time. CPB's forecast cover the macroeconomic aggregates like GDP, investment, consumption exports, inflation, unemployment, wage growth, and the like. ${ }^{27}$ Furthermore, CPB provides an analysis of the implications of this forecast for the government budget and the budget deficit. CPB reports whether expenditure ceilings and revenue targets set in the coalition agreement are met. This information allows the government and the parliament to monitor whether the government lives up to budgetary rules set in the coalition agreement. CPB may also comment on this, e.g. on the merits of adjustments or deviations from the fiscal rules during the financial crisis in 2008 .

The Ministry of Finance does not make its own macro-economic forecast, but relies completely on those of $\mathrm{CPB}$ for making its budgetary estimates. This procedure rules out political pressure to adjust macro-economic forecasts as to avoid the necessity to cut spending or raise taxes. Furthermore, CPB's forecasts for Dutch public finance are based on the same macro-economic assumptions and are published in September simultaneously with the official government budget by the Ministry of Finance. The availability of such an alternative benchmark drastically reduces the attractiveness of being too optimistic on the effects of budget cuts or new taxes in the official government budget.

\footnotetext{
${ }^{27}$ See Bos (2008a), table 2.3.
} 
Table 3.4 The annual budgetary process ( $T$ is the budget year)

\begin{tabular}{|c|c|}
\hline Due dates & Activities \\
\hline November T-2 & $\begin{array}{l}\text { Budget circular from Ministry of Finance to line ministries to start internal } \\
\text { preparations. }\end{array}$ \\
\hline January/February T-1 & $\begin{array}{l}\text { Provisional "Central Economic Plan" by CPB to ministries containing updated } \\
\text { macro-economic and public finance estimates for the budget year and beyond. }\end{array}$ \\
\hline February T-1 & $\begin{array}{l}\text { Line ministries send policy letters to Ministry of Finance indicating spending } \\
\text { priorities and likely budgetary developments. }\end{array}$ \\
\hline March/April T-1 & $\begin{array}{l}\text { Preparation of recalibrated multiyear expenditure framework, with proposed } \\
\text { shifts in allocations/cutbacks brought to cabinet by Ministry of Finance, based on } \\
\text { policy letters. }\end{array}$ \\
\hline March T-1 & "Central Economic Plan" published by CPB on the basis of unchanged policy. \\
\hline April/May T-1 & $\begin{array}{l}\text { Decision by cabinet on expenditure side of the budget. Sent out by Ministry of } \\
\text { Finance to line ministers in "Totals letter". }\end{array}$ \\
\hline May/June T-1 & $\begin{array}{l}\text { Detailed negotiations between Ministry of Finance and line ministries on } \\
\text { composition of their budgets. }\end{array}$ \\
\hline Early June T-1 & $\begin{array}{l}\text { "Provisional Macro Economic Outlook" by CPB to ministries; this contains } \\
\text { updated estimates on the Dutch economy and public finance. }\end{array}$ \\
\hline June T-1 & $\begin{array}{l}\text { "Spring memorandum": parliament is informed on outline of current years } \\
\text { budgetary plans and on budget execution in first quarter. }\end{array}$ \\
\hline August T-1 & $\begin{array}{l}\text { Further fine-tuning of budget on the basis of provisional macroeconomic outlook } \\
\text { provided by CPB to ministries and decision-making on the income side of the } \\
\text { budget. }\end{array}$ \\
\hline 3rd Tuesday September T-1 & $\begin{array}{l}\text { Submission of State budget to parliament together with CPB's Macro-economic } \\
\text { outlook (MEV). }\end{array}$ \\
\hline September T-1 & $\begin{array}{l}\text { Alternative budgets proposals by opposition parties analysed by CPB. Discussion } \\
\text { of State budget and these alternative budget proposals in second and then in first } \\
\text { chamber of parliament. }\end{array}$ \\
\hline Before end December & Approval by both chambers of parliaments of all budget chapters \\
\hline
\end{tabular}

MEV and CEP are discussed in a meeting of the Cabinet. The merit of this discussion is that it offers a platform for an exchange of ideas between CPB and the Cabinet. However, this advantage comes at a cost. First, it yields a larger time lag between finalization of the forecast and their eventual publication. An additional problem is that usually the provisional forecasts are leaked to the press. Leakage to the press is a more general problem, since it hampers consultation of ministries to avoid factual mistakes regarding actual policy and current reform proposals (such mistakes greatly undermine the credibility of a study). Moreover, it does not allow the Cabinet time to think about its first public response. Second, sometimes the Cabinet 
uses the meeting for putting pressure on $\mathrm{CPB}$. This undermines the reputation of $\mathrm{CPB}$ as an independent institute. This pressure regards only the wording of CPB's comments about government policies. There hasn't been any example where ministers (or civil servants on their behalf) have tried to change CPB's forecast of the economy recently. The forecast for the budget deficit itself are more problematic, since CPB has to rely partly on information coming from the Ministry of Finance. To some extent, the ministry has the ability to manipulate the official figure for the budget deficit, for example by shifting expenses or revenues from one year to the other.

In September, CPB analyzes the short run effects of budgetary proposals of opposition parties on a similar basis as the proposals of the government. In September, on request of opposition parties, CPB calculates also the short term effects of their budgetary proposals. These are then discussed in parliament jointly with the official government budget and CPB's MEV.

The macro-economic forecasts by CPB also play an important role in wage negotiations for the public and private sector and for indexing all kinds of long term contracts and agreements. Trade unions and employer federations take CPB's forecast for contractual wage increases as a benchmark for the wage bargaining process. Hence, the forecast is a focal point for the eventual outcome.

This overview of the election cycle and the annual budget process has shown that CPB is deeply embedded in the Dutch political decision-making process. The procedures and timing of the decision-making process are organized in such a way that CPB's forecasts and analyses can be used efficiently and effectively. The evaluation of election platforms provides input for a factual discussion of the pros and cons of various policy proposals in an early stage. The fact that CPB is so deeply embedded in the process implies that CPB's forecasts and analyses benefit from good access to confidential budgetary information. A danger of this formal involvement in the policy making process is that it creates the perception of CPB not being independent.

CPB's central position in the budgetary process requires a clear demarcation between the distinctive roles of CPB and political parties. CPB provides economic analyses and general policy advice. Convincing voters and getting support for a platform of policies is the core business of political parties. Rules and procedures for the timing of CPB's forecasts help both 
sides to respect these roles. For example, CPB organizes a press presentation on its March forecast in CEP, but does not on the publication of the September forecast in MEV, since that publication coincides with the discussion of the budget in parliament. A press presentation at that point in time would interfere with the political discussion. Any change in these rules of conduct causes turmoil. At first sight, these procedures seem only to limit CPB's independence. However, they are a precondition for the authority that is attributed to CPB's judgment by all parties involved, the cabinet, the parliament, and the wider public. The main drawback of these rules is that they are hard to change, and therefore remain in existence even when they have become dysfunctional. For example, the one-month time lag between finalization of the March forecast and the eventual publication is engrained in these traditions, but hinders a proper communication to the wider public.

Welfare economics, using the criterion of Pareto efficiency, provides limited guidance in drawing the demarcation line between positive analysis and politics, as it draws too wide a domain for analysis. Politicians view many topics as normative issues requiring a political judgment that economists routinely consider to be part of the positive domain. Usually, the politicians' point of view is shared by the general public. A fiscal watchdog should be careful not to overstretch, in particular when evaluating election platforms during election time.

The broad scope of CPB's research clearly yields positive externalities in this respect. By providing quantitative analyses of major policy trade-offs, these trade-offs become generally accepted, enabling CPB to apply these analyses in its evaluation of election platforms. In this way, CPB's research establishes a gradual shift of the demarcation line in favour of positive analysis. 


\section{Formal means to ensure independence, quality and relevance}

The formal structure of CPB is laid down in the law of 1947. It is a very short and simple law, which only regulates the composition of the Board of Directors and the existence of the Central Planning Committee (CPC). Formally, the CPC is just an advisory body, but CPB tries to the maximum to treat it as a supervisory body as to preserve CPB's public accountability while precluding intervention from government.

$\mathrm{CPB}$ is a branch of the civil service within the Ministry of Economic Affairs, Agriculture and Innovation. Its director is appointed for the period of seven years by the Minister, in consultation with other members of the government. The personnel evaluation of CPB's director is carried out by the Secretary General of the Ministry. CPB's degree of formal independence is less than that of Statistics Netherlands (CBS), which is an Independent Government Body (ZBO), or the Dutch Court of Auditors, whose independence is even laid down in the constitution. However, tradition and practice developed in Dutch policy formation for 65 years are more important than formal legislation. This tradition is engrained in procedures and rules of conduct, which all parties involved observe in great detail. This practice allows CPB independence in hiring and other human resource management policies, in the conclusions it draws from its research, in its press releases, and in the timing of publication. In practice, the director of CPB decides on CPB's research program. This is crucial. For example, the study on generational accounting may have been developed many years later if the consent of cabinet were a precondition. Obviously, CPB asks all ministries involved for suggestions on topics for the research program, but CPB is free to set its own priorities. CPC advices the director on the research program. Though CPB's independence is engrained in tradition and rules of conduct, there have been frequent attempts of direct interference.

Eighty percent of CPB's funding comes from a lump-sum subsidy from the government. The other twenty percent are additional funds earmarked for specific projects, mostly for the Dutch government, but also for the European Commission. There is a rule constraining CPB to attract at most twenty percent of its lump-sum as additional funding. A larger share would undermine CPB's independence. 
CPB's independence is enhanced by the fact that it also provides analyses on request of opposition parties, trade-unions, employers' organizations, the parliament and the society at large. CPB publications can be downloaded free of charge from its website. An opposition party can ask CPB for a confidential analysis of policy ideas. If a party does not want the conclusions of this analysis to be published, CPB keeps them confidential. However, as soon as anyone refers to this analysis, CPB publishes its report as to avoid that people refer to CPB's research without other people being able to check the arguments.

CPB's independence requires $\mathrm{CPB}$ not to interfere in the political debate and in the competition between political parties for the support of the voters. Its core business is providing arguments derived from economic theory. CPB tries to articulate these arguments as clearly as possible and to as wide an audience as is willing to learn about them. However, convincing voters that they should support one policy above the other is the prerogative of politicians. CPB aims not to interfere in the competition for votes between political parties.

This rule of conduct implies that CPB has a greater freedom in putting forward arguments in the initial stage of the debate on a certain topic, when political parties have not yet taken a strong stance on the topic. CPB times the publication of its research accordingly. It tries to be ahead of the debate. When a debate on a certain topic is running between political parties or between other interest groups, CPB makes a judgment only on request of the parties involved or when a judgment is expected by the general public. CPB tries to avoid being an arbitrator without a mandate, though in practice CPB is often asked to do so.

The position and prestige of CPB would be seriously weakened when the general public or the opposition parties would no longer trust its unbiased judgment. Hence, transparency is a crucial condition. All assumptions and data that underlie CPB's analyses are public and verifiable. Pressure put on CPB by Ministers or Ministries evokes counter forces. The parliament and the press are quick in scenting trouble. The permanent Parliamentary Commission for Economic Affairs regularly invites the director of CPB to discuss recent publications of the Bureau. The civil service tries to avoid direct contact of ministers with $\mathrm{CPB}$ in case of dispute as to avoid the public image that CPB is suspect to pressure from the government. And the free press is perhaps the best ally to protect independence in an open democratic society. 
The undisputed scientific quality of CPB's research and analyses is a precondition for its reputation. About every five years, both the policy relevance and scientific quality of CPB work are assessed by visitation committee. These committees are appointed by CPC and report to the CPC. All members of the committee for policy relevance are Dutch. The committee for scientific quality is made up of international experts, only one member being Dutch (see e.g. CPB, 2003c, 2010). The most recent scientific committee was chaired by Martin Hellwig. ${ }^{28}$ The committee concluded that CPB provided high quality work on the crossroads of academic research and policy making, that its methodology is up-to-date and up-to-standard. Scientific quality could be further enhanced by a more systematic effort at publishing in academic journals and a more systematic use of links to the academic community. The committee states that too many resources are devoted to model-building at the expense of other forms policy-relevant empirical work, including a more thoughtful use of theory to guide descriptive analysis and reduced-form empirical work. The committee also advocates spending fewer resources on the evaluation of election programs. CPB has not followed the latter advice.

\footnotetext{
${ }^{28}$ The 2003-committee was chaired by K. Zimmermann (IZA, Germany). Other members of the 2010 committee were R. Boadway (Queens University, Toronto, Canada), J. Elmeskov (OECD), R. Griffith (IFS, United Kingdom), T. Andersen (University of Arhus, Denmark), and S. van Wijnbergen (University of Amsterdam, Netherlands).
} 


\section{Conclusions}

What can economists contribute to day to day policy making? Coats $(1989$, p. 118) takes a modest point of view. Forget about optimal policies. The most economists can hope to achieve is "damage minimization". This can be accomplished "by modifying, refining, or even blocking the ill-considered policy proposals by laymen - for example, by emphasizing the opportunity costs of a given action or, more broadly, the system-wide implications of a specific policy". When successful, this contributes to a fairer public policy that is less vulnerable to specific lobbies and that is less hampered by unintended consequences. CPB's 65 years experience as a fiscal watchdog yields some lessons on what factors help in realizing this modest achievement of minimizing the damage that bad policies can do.

Firstly, a reputation of quality and independence is crucial for the success of a watchdog. Building such a reputation takes time. CPB benefited from the reputation of its founder and first director, Jan Tinbergen, both as a scientist and as moral spokesman in Dutch society. Apart from that, CPB is fully transparent about its inputs, its methodology, and the way it establishes its conclusions. Furthermore, CPB undertakes permanent quality control of its research, and let this quality be reviewed by outside monitoring commissions every five years.

Secondly, the effectiveness of CPB depends crucially on a clear demarcation of the distinctive roles of $\mathrm{CPB}$ and political parties. However, convincing voters that they should support the one policy above the other is the prerogative of politicians. CPB aims not to interfere in the competition for votes between political parties. It tries to be ahead of the political debate. As soon as political positions are taken, it becomes very difficult for CPB to provide sensible economic arguments. Procedures and rules play also an important role to make the demarcation line between the roles of the expert and the politicians visible, as they clarify for the general public whether a particular debate is about positive analysis or about political preferences. Both are legitimate, but it is wise to clearly distinguish between the two.

Thirdly, welfare economics provides little guidance in drawing the demarcation line between positive analysis and political judgment, since the concept of Pareto efficiency as applied in welfare economics draws the line too much in favour of positive analyses, leaves too little 
scope for political judgement and ignores the imperfections in markets. For this reason, the scope of a fiscal watchdog's research should not be constrained too much. The broad scope of CPB's analyses has contributed to shared public understanding of relevant trade-offs and policy options. That enhanced CPB's reputation in society -e.g. assumptions underlying CPB's models were vehemently debated- and it helped the political arena to come to the right conclusion.

Fourthly, being only at arm's length of the government has the advantage of getting inside information and being effective in the daily policy making process, but the disadvantage that the actual or perceived independence is more difficult to maintain. To some extent, the role of $\mathrm{CPB}$ in Dutch fiscal policy is unique in the world and reflects typical Dutch circumstances (e.g. a prevalence of coalition governments and the independent position of CPB since World War II). Nevertheless, the Dutch fiscal institutions, procedures and specific rules could be relevant and transferable to other countries. The Dutch model with a mix of an independent expert institute and a high-level advisory group on fiscal policy can be interesting. 


\section{References}

Auerbach, A.J., J. Gokhale and L.J. Kotlikoff, 1991, Generational accounts - A meaningful alternative to deficit accounting, NBER Working Paper 3589.

Boogaard, A. van den, 1998, Configuring the economy; the emergence of a modelling practice in the Netherlands, 1920-1955, Thela Thesis.

Bos, F., 2006, The development of the Dutch national accounts as a tool for analysis and policy, Statistica Neerlandica, vol. 60, nr. 2, pp. 225-258.

Bos, F., 2008a, The Dutch fiscal framework; history, current practice and the role of the CPB, OECD Journal on Budgeting, pp. 1-48. Also published as CPB Document 150.

Bos, F., 2008b, Uses of national accounts: history, international standardization and applications in the Netherlands, MPRA Paper 9387, University Library of Munich, Germany.

Bos, F. and C. Teulings, 2010, CPB and Dutch fiscal policy in view of ageing and the financial crisis, CPB Document 218.

Bos, F. and C. Teulings, 2011, Evaluating election platforms: a task for fiscal councils? Scope and rules of the game in view of 25 years of Dutch practice, Paper to be published in the Proceedings of the Banca d'Italia Fiscal Policy Workshop 2011, also downloadable as MPRA Paper 31536, University Library of Munich, Germany

Butter, F. den, 2009, The Industrial Organisation of Economic Policy Preparation in The Netherlands, ch.9 in: P. Weingart, J. Lentsch, eds., Between Science and Policy: Quality Control and Scientific Policy Advice, pp. 227-84, Cambridge University Press, Cambridge.

Coats, A.W., 1989, Economic ideas and economists in government. In: D. Colander and A.W. Coats (eds.), The spread of economic ideas, Cambridge University Press, pp. 109-118. 
CPB, 1992a, Scanning the future; a long-term scenario study of the world economy 1990-

2015, CPB Special Publication nr. 1, SDU Publishers, The Hague.

CPB, 1992b, Nederland in drievoud, een scenario studie van de Nederlandse economie 19902015, CPB Special Publication nr. 2, SDU Publishers, The Hague.

CPB, 1997, Challenging neighbours; rethinking German and Dutch economic institutions, Springer, Berlin and New York.

CPB, 2010, Focusing on quality; report from the CPB Review Committee 2010 (M.F. Hellwig, T.M. Andersen, R.W. Boadway, J. Elmeskov, R. Griffith and S. van Wijnbergen).

Debrun, X., M. Gérard, J. Harris, 2012, Fiscal policies in crisis mode: has the time for fiscal councils come at last?, Paper presented at the $4^{\text {th }}$ Annual Meeting of OECD Parliamentary Budget Officials and Independent Fiscal Institutions, 22-24 February 2012, Paris.

Don, F.J.H. and J. Verbruggen, 2006, Models and methods for economic policy; 60 years of evolution at CPB, Statistica Neerlandica, vol. 60, nr 2, pp. 145-170. Also published as CPB Discussion Paper 55.

Donders, J.H.M. and J.J. Graafland, 2000, CPB models and employment policy in the Netherlands, Chapter 2, pp. 10-25, in Butter and Morgan (eds.), Empirical models and policymaking: interactions and institutions. Also published in Economic Modelling, 1998, Vol 15, Issue 3, pp. 341-456.

Gelauff, G.M.M., and J.J. Graafland, 1994, Modelling welfare state reform, North-Holland, Amsterdam.

Graafland, J.J., R.A. de Mooij, A. Nibbelink and A. Nieuwenhuis, 2001, MIMICing Tax Reform, Elsevier Science, Amsterdam.

Graafland, J.J. and A.P. Ros (eds.), 2003, Economic Assessment of Election Programmes: Does it Make Sense?, Kluwer Academic Publishers, Dordrecht/Boston. 
Hartog, H. den and H.S. Tjan, 1976, Investments, Wages, Prices and Demand for Labour, De Economist, no. 124, pp. 32-55.

Horst, A. van der, L. Bettendorf, N. Draper, C. van Ewijk, R. de Mooij en H. ter Rele, 2010, Vergrijzing verdeeld; toekomst van de Nederlandse overheidsfinanciën [Ageing and distribution; the future of Dutch public finance], CPB Special Publication 86.

IMF, 2006, Kingdom of the Netherlands: report on the observance of standards and codesFiscal Transparency Module, and the Aide-Mémoire regarding the fiscal framework, IMF Country report no. 06/124.

OECD, 2010, Economic Outlook, November, no. 88.

Passenier, J., 1994, Van planning naar scanning; een halve eeuw Planbureau in Nederland, Wolters-Noordhof, Groningen.

Studiegroep Begrotingsruimte (Dutch Official advisory group on fiscal policy), various reports, Ministry of Finance, The Hague.

Stiglitz, J.E., A. Sen and J.P. Fitoussi, 2009, Report by the Commission on the Measurement of Economic Performance and Social Progress.

Tinbergen, J., 1956, Economic policy, principles and design, North Holland, Amsterdam.

Zanden, J.L. van, 2010, De spagaat van het CPB, Me Judice, year 3, 24 December 2010. 


Publisher:

CPB Netherlands Bureau for Economic Policy Analysis

P.O. Box $80510 \mid 2508$ GM The Hague

$\mathrm{T}(070) 3383380$

March 2012 | ISBN 978-90-5833-549-4 